\title{
Effect of High BMI on Endometriosis - A Chart Review Study
}

\author{
Dr. Megren Al Beaiji ${ }^{1,2,3}$, Lubna Khan ${ }^{2,3^{*}}$, Haitham Magdie Felimban ${ }^{1,2,3,4}$, Dr. Shoeb Qureshi ${ }^{1}$, \\ Hanan Al-Kadri ${ }^{1,2,3}$ \\ ${ }^{1}$ King Saud bin Abdulaziz University for Health Sciences \\ ${ }^{2}$ King Abdul-Aziz Medical City, National Guard Health Affairs \\ 3 King Abdullah International Medical Research Centre
}

4 Security Forces Hospital Program, Riyadh, KSA

*Corresponding Author: Lubna Khan, Department of Obs and Gynecology, King Abdulaziz Medical City , National Guards, Riyadh, Saudi Arabia, Email:Lubnamurshid@yahoo.com

\begin{abstract}
Objective: To compare the effect of High BMI on severity Endometriosis.

Population or Sample: All women who have histopathological diagnosis of endometriosis during laparoscopic or laparotomy management of their disease between the years 2006-2013.

Methods: We have selected 412 patients and divided them in to two groups according to their BMI. Group G1 (BMI less than 24) had 64 patients and Group G2 (BMI of 24 and above) had 348 patients. Patients' information sheet has included their demographic data such as sign and symptoms of disease. Diagnostic modalities like USS, MRI, CT scan and Laparoscopy was incorporated in the sheets. patient's related risk factor and type of treatment offered in terms of medical or surgical management were also included in the information sheet.

Data was analyzed using SPSS Statistical Analysis Package version 20. Descriptive statistics was used to analyze maternal characteristics. Student t-test and chi-square test was used for Univariate analysis, after assessing the normality of the variables to decide the potential covariates and a p-value of less than 0.05 was selected to show statistical significance.
\end{abstract}

Results: Lower BMI $(<24)$ is associated with higher incidence of disease related sign and symptoms $(p-0.01)$ and prevalence of infertility (0.01) and menopause (0.001).

Conclusion: Low BMI (group G1) was found to have increase severity of the disease, menstrual irregularities and with prevalence of infertility but still more research is required to observe the association of Obesity and Endometriosis, and to know if we can predict the incidence of endometriosis by preadolescent BMI.

Keywords: Dysmenorrhea, Dyschesia, Dyspareunia, Pelvic pain, Body mass index.

\section{INTRODUCTION}

Endometriosis is a benign, chronic estrogen dependent gynecological disorder, defined as presence of endometrial gland and stroma at extra uterine sites (ovaries, rectovaginal septum, ureter, urinary bladder, pericardium and pleura) [1]. It is associated with many distressing and debilitating symptoms such as pelvic pain, dysmenorrhea, dyspareunia, pelvic mass and infertility [2].Incidence of endometriosis is unknown due to the presence of many asymptomatic patients, incidental discovery at laparoscopy or laparotomy, low sensitivity in some imaging modalities and genetic predisposition [3]. Sen -Wen Tang et al [5] found out that prevalence of Endometriosis was $42 \%, 33 \%, 25 \%$ and $12 \%$ respectively for women operated for Pelvic adhesions, infertility, uterine fibroid and sterilization. The researchers conclude that overall incidence of Endometriosis in asymptomatic patients was $24.7 \%$.

Endometriosis is one of the most common gynecological disorder (70- 90\%) associated with pelvic pain syndrome [5].

Pathogenesis is not yet clear and is claimed to be either the result of retrograde menstruation or 
lymphatic or vascular dissemination. Another suggested pathogenesis is metaplasia or induction theory, hormonal dependence and immune system. Leptin an adipocyte derived hormone have been linked with endometriosis and found elevated in over weight patients in direct correlation with BMI [9]. Leptin is well known to serve as a signal to inform the central nervous system about the state of fat stores [20]. However, besides its role in obesity and metabolic disorders, Leptin has lately been suggested to be involved in previously unexpected functions, specifically the regulation of angiogenesis ${ }^{21}$ and immune response [22;23]; which are among the most important processes implicated in the development of endometriosis $[25,26]$.

Many studies have been performed so far researching the relationship of High BMI with the incidence of Endometriosis. Results were conflicting, some $[6,8.9,10]$ observed an increase prevalence of Endometriosis with lower BMI $(<18)$, while others Moen et al [12]found no association with exercise, smoking or BMI

Laparoscopy is the gold standard for Diagnosis of Endometriosis [17]. Transvaginal sonography (TVS) is useful in diagnosing and ruling out rectal endometriosis (sensitivity 91\% and specificity $98 \%$ ). Usefulness of 3D sonography in the diagnosis of endometriosis is not well established. MRI is not useful to diagnose or exclude the disease (sensitivity38\% and specificity 74\%) [17].

Overall, Endometriosis is a chronic disease that requires lifelong management plan with a goal of maximizing use of medical treatment and avoiding repeating surgical procedures [4] Despite extensive research on endometriosis, the optimal management is unclear. Moreover, treatment decision is usually individualized taking into consideration its symptoms, location, women's desire for pregnancy, age, medication side effects, surgical complication and cost etc [4].

The characteristics of endometriosis between Saudi women are unknown being with high parity and long reproductive span. In our study we mainly discussed the incidence of Endometriosis and its complications in relation to BMI. This retrospective chart review study was performed from 2006- 2013 to evaluate the Risk and complication of the disease in relation to BMI for our specific demographic population.

\section{MATERIALS AND MeTHOD}

\subsection{Settings}

We have conducted this retrospective chart review study at King Abdul-Aziz Medical City (KAMC) Riyadh, King Fahd National Guard Hospital (KFNGH), Department of Obstetrics and Gynecology from January 2006-December 2013.

\subsection{Ethics}

The approval of King Abdullah International Medical Research Center (KAIMRC) research and ethical committee was obtained prior to the research conduction.

\subsection{Study Subjects}

All women who have histopathological diagnosis of their disease during either laparoscopic or laparotomy management between the years 2006-2013 were included. We have divided our patients according to their body mass index of less than 24 (G1) or more than 24(G2).

\subsection{Study Design}

Retrospective chart review study.

\subsection{Sample Size}

Sample size was 412 patients. Group G1 (BMI less than 24) had 64 patients and Group G2 (BMI of 24 and above) had 348 patients.

\subsection{Data Collection}

Patients' information charts consisted of demographic data such as: patients name, age, weight, height and parity. symptoms (Dysmenorrhea, Hematochezia, abdominal pain etc.) and signs (adnexal mass, abdominal mass, Uterosacral ligament Nodularities etc.) were included in the charts. Diagnostic modalities like USS, MRI, CT scan and Laparoscopy were incorporated in the sheets. Information also contained patient's related risk factor (infertility, early Menarche, late menopause, family history) and the type of treatment offered in terms of medical or surgical management. At the end all the cases were confirmed by Histopathology.

\subsection{Data Analysis}

Data was analyzed using SPSS Statistical Analysis Package version 20. Descriptive statistics (such as means, standard deviations, frequencies, etc.) were used to summarize the maternal characteristics. Student t-test and chisquare test were used for Univariate analysis, after assessing the normality of the variables to 
decide the potential covariates and a p-value of less than 0.05 was selected to show statistical significance. Univariate analysis used to compute the adjusted odds ratio and its $95 \%$ confidence interval of confounding factors after assessment of normality of residuals and excluding the effect of any possible interactions.

\section{RESULTS}

\subsection{Patient Characteristics}

Patients were divided in to two groups according to their age, parity and nationality. Mean age was $35-45$ in both groups. Parity was from 2-4 children. Among Saudi nationals $89.4 \%$ were among BMI 24 and above and $76 \%$ were included in lower BMI group.

Table1. Patient characteristics

\begin{tabular}{|l|l|l|}
\hline \multicolumn{1}{|c|}{$\begin{array}{c}\text { Patient } \\
\text { Characteristic: }\end{array}$} & $\begin{array}{c}\text { Less than } 24 \\
(\mathrm{n}=64)\end{array}$ & $\begin{array}{c}\text { 24 and above } \\
(\mathrm{n}=348)\end{array}$ \\
\hline Age & $33.8 \pm 9.7$ & $44.6 \pm 11.2$ \\
\hline Parity & $1.8 \pm 2.6$ & $4.7 \pm 3.8$ \\
\hline Nationality- Saudi & $49(76.6 \%)$ & $311(89.4 \%)$ \\
\hline
\end{tabular}

\subsection{Screening Modalities}

Patients were screened using ultrasound, MRI and CT scan. There was no significant difference among sensitivities of three available modalities in both patients groups. With the ultrasound out of 64 patients 60 were screen positive from BMI group less than 24. 335 patients out of 348 were screen positive from higher BMI group (>24) the difference was not statistically significant with a $\mathrm{p}$ value of 0.35 .

MRI was able to diagnose Endometriosis in $9.4 \%$ of patient from lower BMI group and $6.6 \%$ of patient from BMI $>24$ (p value- 0.43 ). Where CT scan has been used to diagnose Endometriosis, results were $4.7 \%$ and $3.4 \%$ respectively from low $(<24)$ and high BMI (>24) group with a p value of 0.63 . That showed that there was no significant difference among sensitivities of available screening modalities.

Table2. Method of Screening

\begin{tabular}{|c|c|c|c|}
\hline \multirow[b]{2}{*}{$\begin{array}{l}\text { Method of } \\
\text { Screening }\end{array}$} & \multicolumn{2}{|c|}{ BMI } & \multirow[b]{2}{*}{$\begin{array}{c}\text { P- } \\
\text { Value }\end{array}$} \\
\hline & $\begin{array}{c}\text { Less than } \\
\mathbf{2 4} \\
(\mathrm{n}=64)\end{array}$ & $\begin{array}{c}24 \text { and } \\
\text { above } \\
(n=348)\end{array}$ & \\
\hline USS & $60(93.8 \%)$ & $335(96.3 \%)$ & 0.35 \\
\hline MRI & $6(9.4 \%)$ & $23(6.6 \%)$ & 0.43 \\
\hline CT Scan & $3(4.7 \%)$ & $12(3.4 \%)$ & 0.63 \\
\hline
\end{tabular}

USS- ultrasound, MRI- Magnetic resonance imaging, CT- computed Tomography

\subsection{Patient's Signs and Symptoms}

BMI has positively led to increase rate of complications associated with Endometriosis. An increased incidence of dysmenorrhea ( $\mathrm{p}$ 0.0001 ), abdominalmass (p-0.006) and adnexal mass (p-0.04). There was non-significant risk of Uterosacral ligament involvement (p-0.13), Nodularities (p-0.18) and incisional lump in relation to body mass index.

Table3. Patient signs and symptoms in relation to $B M I$

\begin{tabular}{|c|c|c|c|}
\hline \multirow{2}{*}{$\begin{array}{c}\text { Patient } \\
\text { Symptoms } \\
\text { and Signs }\end{array}$} & \multicolumn{2}{|c|}{ BMI } & \multirow{2}{*}{$\begin{array}{c}\text { P- } \\
\text { Value }\end{array}$} \\
\hline & $\begin{array}{l}\text { Less } \\
\text { than } 24 \\
(n=64)\end{array}$ & $\begin{array}{l}24 \text { and } \\
\text { above } \\
(n=348)\end{array}$ & \\
\hline $\begin{array}{l}\text { Abdominal } \\
\text { Pain }\end{array}$ & $\begin{array}{l}28 \\
(43.8 \%)\end{array}$ & $\begin{array}{l}143 \\
(41.1 \%)\end{array}$ & 0.69 \\
\hline $\begin{array}{l}\text { Dysmenorrhe } \\
\text { a }\end{array}$ & $\begin{array}{l}25 \\
(39.1 \%) \\
\end{array}$ & $\begin{array}{l}71 \\
(20.4 \%) \\
\end{array}$ & 0.001 \\
\hline $\begin{array}{l}\text { Abdominal } \\
\text { mass }\end{array}$ & $\begin{array}{l}25 \\
(39.1 \%)\end{array}$ & $\begin{array}{l}79 \\
(22.7 \%)\end{array}$ & 0.006 \\
\hline $\begin{array}{l}\text { Utero sacral } \\
\text { ligament }\end{array}$ & $2(3.1 \%)$ & $3(0.9 \%)$ & 0.13 \\
\hline Nodularities & $1(1.6 \%)$ & $1(0.3 \%)$ & 0.18 \\
\hline Adnexal mass & $\begin{array}{l}29 \\
(45.3 \%)\end{array}$ & $\begin{array}{l}111 \\
(31.9 \%)\end{array}$ & 0.04 \\
\hline
\end{tabular}

$n=$ number, $B M I=$ body mass index

\subsection{Patient Associated Risk Factors}

Table4. Patient associated risk factors and operative complications

\begin{tabular}{|l|l|l|l|}
\hline \multirow{2}{*}{$\begin{array}{c}\text { Patient } \\
\text { associated risk } \\
\text { factors and } \\
\text { operative } \\
\text { complications }\end{array}$} & $\begin{array}{l}\text { Less than } \\
\mathbf{2 4}(\mathrm{n}=64)\end{array}$ & $\begin{array}{c}\text { 24and } \\
\text { above } \\
(\mathrm{n}=348)\end{array}$ & P-Value \\
\hline Menarche & $1(1.6 \%)$ & $3(0.9 \%)$ & 0.60 \\
\hline Fertility & $\begin{array}{l}35 \\
(54.7 \%)\end{array}$ & $\begin{array}{l}131 \\
(37.6 \%)\end{array}$ & 0.01 \\
\hline Menopause & $3(4.7 \%)$ & $\begin{array}{l}93 \\
(26.7 \%)\end{array}$ & 0.0001 \\
\hline $\begin{array}{l}\text { Pattern of cycle } \\
\text { list }\end{array}$ & $\begin{array}{l}(37.5 \%) \\
(36.5 \%)\end{array}$ & $\begin{array}{l}127 \\
(36.88\end{array}$ \\
\hline Family Hx & $2(3.1 \%)$ & $3(0.9 \%)$ & 0.13 \\
\hline $\begin{array}{l}\text { Endometrial } \\
\text { Infertility }\end{array}$ & $2(3.1 \%)$ & $9(2.6 \%)$ & 0.81 \\
\hline $\begin{array}{l}\text { Intra-op } \\
\text { complication }\end{array}$ & $1(1.6 \%)$ & $9(2.6 \%)$ & 0.63 \\
\hline
\end{tabular}

Low Body mass index of less than 24 is associated with significant increased risk of infertility (p-0.01) and late menopause while high BMI is linked to early Menopause. There was some associated higher risk with early menarche that did not reach statistical significance ( $\mathrm{p}-0.60)$. Cycle irregularity is also more common with low BMI group (p-0.88). 
Endometriosis has been associated with positive family history in $3.1 \%$ of cases in lower BMI group and in $0.9 \%$ between the higher BMI (p0.13 ). There is increased risk of intraoperative complications in overweight group, but this increase did not reach to clinical significance.

\section{DisCUSSION}

In our study we have observed that incidence of endometriosis and related signs and symptoms were increased with BMI below 24. Fertility issues were also higher among patients with low BMI.

Recent studies from both the European Journal of Obstetrics and Gynecology [17] and the International Journal of Gynecology Obstetrics [16] suggest that women with endometriosis actually tend to have lower body mass indexes (BMIs) than women without the disease.

Missmer SA et el [6], observed in his study that Endometriosis has an inverse relationship with BMI in younger age group. They associate this decreased risk in obese patients with greater prevalence of oligomenorrhea and infertility in this class. However, this study had selection bias as study group consisted of infertile women only.

Laffey Pallet MC et el [7], has studied the association of BMI with disease severity (superficial, infiltrating and ovarian Endometriosis) and conclude that independent of confounding variables patients with lower BMI are at higher risk of deep infiltrating Endometriosis. Ferrero et el [8] and Signorelli LB et el ${ }^{11}$ have supported this observation.

Moen $\mathrm{H}$ etal [12] have performed a cross sectional study to look for factors associated with Endometriosis. They found out an increased risk with early menarche and frequent menstrual periods. No association was found between endometriosis and modifiable life style factors like lack of exercise, smoking or BMI. We also have observed the same results in our study, but results didn't reach clinical significance (p- 0.60)

Queensland Institute of Medical Research in Australia compared over 500 women with and without endometriosis in relation to early menstrual characteristics before the onset of disease. They also found out that late Menarche (over 14) was associated with decreased risk.

Endometriosis is a disease that is mainly diagnosed in reproductive-aged group women. This is probably because the main worry with endometriosis (other than the bothersome pain) is infertility. In reality, most of the signs and symptoms of endometriosis start much earlier in life, when these women are actually little girls.

In contrast to the above evidences some researcher find that Strong period pain and childhood obesity could be a precursor of endometriosis, a disease that affects anywhere from 10 to 15 percent of women. In a study's press release, researchers warn that an overweight 10-year old has double the risk of developing endometriosis later in her life ${ }^{19}$ Coexistence of elevated Leptin levels with obesity had been observed.

Mantzoros etel [21] has an interesting observation in relation to Leptin levels and found statistically significant $(\mathrm{P}<0.05)$ increase in Leptin levels in serum $(30.3+/-14.8 \mathrm{ng} / \mathrm{mL})$ and peritoneal fluid $(35.9+/-17.4 \mathrm{ng} / \mathrm{mL})$ of patients with endometriosis, compared with control population (serum, $15.6+/-8.4$; PF, 17.5 $+/-7.2 \mathrm{ng} / \mathrm{mL}$ ). Higher levels of Leptin were observed in the earlier stages of endometriosis than advanced-stage disease. These observations were supported by other researchers as well.

In our study though the observation of increase incidence, severity and complication of the disease were more in lower BMI group, but high BMI do have an association with early menopause and intraoperative complications.

Association of Endometriosis to serum Leptin concentration has been a topic of debate and more broad scale research is required to associate it with early stage endometriosis, before the more debilitating deep infiltrating form sets in.

\section{CONCLUSION}

Low BMI (group G1) was found to beinversely proportional to the severity of the disease, menstrual irregularities and with prevalence of infertility. More research is required to observe the association of Leptin with Obesity and endometriosis. Such research may allow us to know if we can predict the disease happening in future by pre-adolescent BMI and Leptin levels.

\section{DETAILS OF ETHICS APPROVAL}

All of the patients who participated in this trial provided informed written consent and the trial was approved by the King Abdullah International Medical Research Center (KAIMRC) research and ethical committee and the Institute Review Board (IRB). 


\section{REFERENCES}

[1] Redwine DB. Diaphragmatic endometriosis: diagnosis, surgical management, and long-term results of treatment. Fertil Steril 2002; 77:288.

[2] Sangi-Haghpeykar H, Poindexter AN 3rd. Epidemiology of endometriosis among parous women. ObstetGynecol 1995; 85:983

[3] Chatman DL, Ward AB. Endometriosis in adolescents. J Reprod Med 1982; 27:156.

[4] Practice Committee of American Society for Reproductive Medicine. Treatment of pelvic pain associated with endometriosis. Fertil Steril 2008; 90:S260.

[5] Wen Tang SW1 J Chin Med Assoc. 2016 Nov; 79(11):577-582. doi: 10.1016/ j.jcma.2016.04. 006. Epub 2016 Aug 2016

[6] Missmer SA,Am J Epidemiol. 2004 Oct 15;16 0(8):784-96.

[7] 7-Laffay Pillet MC,Deep infiltrating endometr iosis is associated with markedly lower body mass index: a 476 case-control study. Hum Reprod. 2012 Jan; 27(1):265-72. doi: 10.1093/ humrep/der346. Epub 2011 Oct 24

[8] 8-FerreroS1:Body mass index in endometriosis Eur J ObstetGynecolReprod Biol. 2005 Jul 1;121(1):948.

[9] Nikolaos Machairiotis, ${ }^{1}$ Aikaterini Stylianaki, ${ }^{2}$ Georgios Dryllis, Diagn Pathol, 2013; 8: 194. Published online 2013 Dec 2. doi: [10.1186/17 46-1596-8-194]

[10] Berube $S$ et elCharacteristics related to the prevalence of minimal or mild endometriosis in infertile women. Canadian Collaborative Group on Endometriosis Epidemiology. 1998 Sep;9 (5):504-10

[11] Signorello LB et el : Epidemiologic determinants of endometriosis: a hospital-based case-control study. Ann Epidemiol. 1997 May; 7(4):267-741

[12] Moen MH et el : Epidemiology of endometriosis in a Norwegian county. Acta ObstetGynecol Scand. 1997 Jul;76(6):559-62
[13] DiwadkerGB et el:Surgical management of pain and infertility secondary to endometriosis SeminReprod Med. 2011 Mar;29(2):124-9. doi: 10.1055/s-0031-1272474. Epub 2011 Mar 24.

[14] Ozkan S et el: Advances in treatment options of endometriosis GynecolObstet Invest. 2009; 67 (2):81-91. doi: 10.1159/000163071. Epub 2008 Oct 16

[15] Olive DL et el:Endometriosis and infertility: what do we do for each stage? Curr Womens Health Rep. 2003 Oct;3(5):389-94.

[16] Practice Committee of the American Society for Reproductive Medicine. Endometriosis and infertility Fertil Steril. 2006 Nov;86(5 Suppl 1):S156-60.

[17] Dun Selman GA, Vermeulen N, Becker C, Calhaz-Jorge C, D'Hooghe T, De Bie B, Heikinheimo O, Horne AW, Kiesel L, Nap A, Prentice A, Saridogan E, Soriano D, Nelen W. ESHRE guideline: management of women with endometriosis. Hum Reprod. 2014 Mar;29(3):400-12. doi: 10.1093/humrep/ det457. Guideline of the European Society of Human Reproduction and Embryology Management of women with endometriosis

[18] SOGC clinical practice guidelines: Endometrio sis: Diagnosis and Management-24 july 2010

[19] Metarese G1etel:Increased leptin levels in serum and peritoneal fluid of patients with pelvic endometriosisJ Clin Endocrinol Metab. $2000 \mathrm{Jul} ; 85(7): 2483-7$

[20] Sarra F P et el: Multiple cytokines and acute inflammation raise mouse leptin levels: potential role in inflammatory anorexiaJ Exp Med. 1997 Jan 6;185(1):171-5.

[21] Mantzoros CS etel:Leptin concentrations in relation to body mass index and the tumor necrosis factor-alpha system in humansClin EndocrinolMetab. 1997 Oct;82(10 v):3408-

Citation: Megren Al Beaiji, Lubna Khan, Haitham Magdie Felimban, Shoeb Qureshi, Hanan Al-Kadri. Effect of High BMI on Endometriosis - A Chart Review Study. ARC Journal of Public Health and Community Medicine. 2019; 4(1):1-5.DOI:dx.doi.org/ 10.20431/2456-0596.0401001.

Copyright: (C) 2019 Authors. This is an open-access article distributed under the terms of the Creative Commons Attribution License, which permits unrestricted use, distribution, and reproduction in any medium, provided the original author and source are credited. 